\title{
$1{ }^{\circ}$ CONAERG \\ CONGRESSO INTERNACIONAL DE ERGONOMIA APLICADA
}

\section{SOB O FOCO DA ERGONOMIA COGNITIVA: O CONHECIMENTO MODIFICA O COMPORTAMENTO}

\author{
Silvânia Rodrigues de Paula (1) \\ Edgard Tomás Martins (2) \\ (1) Universidade Federal de Pernambuco, Mestre \\ e-mail:silvania.rpaula@gmail.com \\ (2) \\ Universidade Federal de Pernambuco \\ UFPE , Doutor \\ e-mail: edgardpiloto@gmail.com
}

\begin{abstract}
RESUMO
O aumento no número de acidentes de trabalho e afastamento de trabalhadores de postos de trabalho contribui para aumento do custo de produção, fez com que os empresários comecem a pensar como gerenciar e capacitar os trabalhadores de modo focado sobre as causas envolvidas. $\mathrm{Da}$ necessidade das empresas de buscarem a redução e / ou eliminação de acidentes de trabalho. Considerando a ergonomia objetivando modificar os sistemas de trabalho para adequar a atividade existente às características, habilidades e limitações das pessoas com vistas ao seu desempenho eficiente, confortável e seguro, os empresários consideram a aplicação da ergonomia, mesmo que incipiente.
\end{abstract}

\begin{abstract}
The increase in the number of accidents and removal jobs of workers contributes to increased cost of production, made entrepreneurs start thinking about how to manage and enable focused way of working on the causes involved. The need of the companies to seek the reduction and / or elimination of accidents, considering ergonomics aiming to modify work systems to suit existing activity to the characteristics, abilities and limitations of people with a view to its efficient performance, comfortable and safe, entrepreneurs consider the application of ergonomics, even if incipient.
\end{abstract}

\section{INTRODUÇÃO}

Como uma disciplina aplicada, ergonomia traz os resultados de modelagem científica de tratamentos realidade e o levantamento do estado da arte do problema para o desenvolvimento da tecnologia de interfaces para a concepção, análise, teste, padronização e controle dos sistemas de trabalho. A partir da necessidade existente nas organizações, a ergonomia vem se desenvolvendo em seus estudos e aplicações, deixando de ter seu caráter focado em aspectos físicos do trabalho, passando a olhar o mesmo de modo completo, considerando os aspectos cognitivos envolvidos nas atividades realizadas pelos trabalhadores. 
De acordo com Abrahão et al (2009), a cognição é um conjunto de processos mentais que permite às pessoas buscar, armazenar e utilizar diferentes tipos de informações do ambiente. É a partir dos processos cognitivos que o indivíduo adquire e produz conhecimentos.

Os Ergonomistas atuam, contribuindo cada vez mais para a concepção de sistemas de trabalho que promovam o desenvolvimento de competências e assegurem a saúde dos trabalhadores e a segurança operacional, de acordo com Abrahão et al. 2009. Com a identificação de fatores cognitivos que contribuem mais fortemente no comportamento humano durante a execução de atividades no trabalho, podem-se estabelecer ações mais específicas e dirigidas para evitar acidentes.

\section{CONTEXTUALIZAÇÃO}

A definição internacionalmente aceita hoje chama a atenção para três aspectos: o tipo de conhecimento e suas inter-relações, o foco sobre as mudanças e os critérios para a ação ergonômica. A consideração destes aspectos configura contemporaneamente a ergonomia como uma disciplina de síntese entre os vários aspectos do conhecimento sobre as pessoas, tecnologia e organização. Para uma ordenação desse campo empregamos uma classificação destes conteúdos, como sugerido pela Associação Internacional de Ergonomia (IEA): ergonomia física, cognitiva e organizacional. A figura 1 descreve o processo cognitivo. Em termos cognitivos o ser humano transforma a informação de natureza física em informações de natureza simbólica e a partir desta em ação nas interfaces. Sua concepção nos é trazida pelo campo da ciência cognitiva, que visa o estudo do conhecimento virtual, o conjunto das condições estruturais e funcionais mínimas de detecção, para representar, recuperar e usar informação (VIDAL, 2000).

Figura 1 - Processo perceptivo, cognitivo e motor

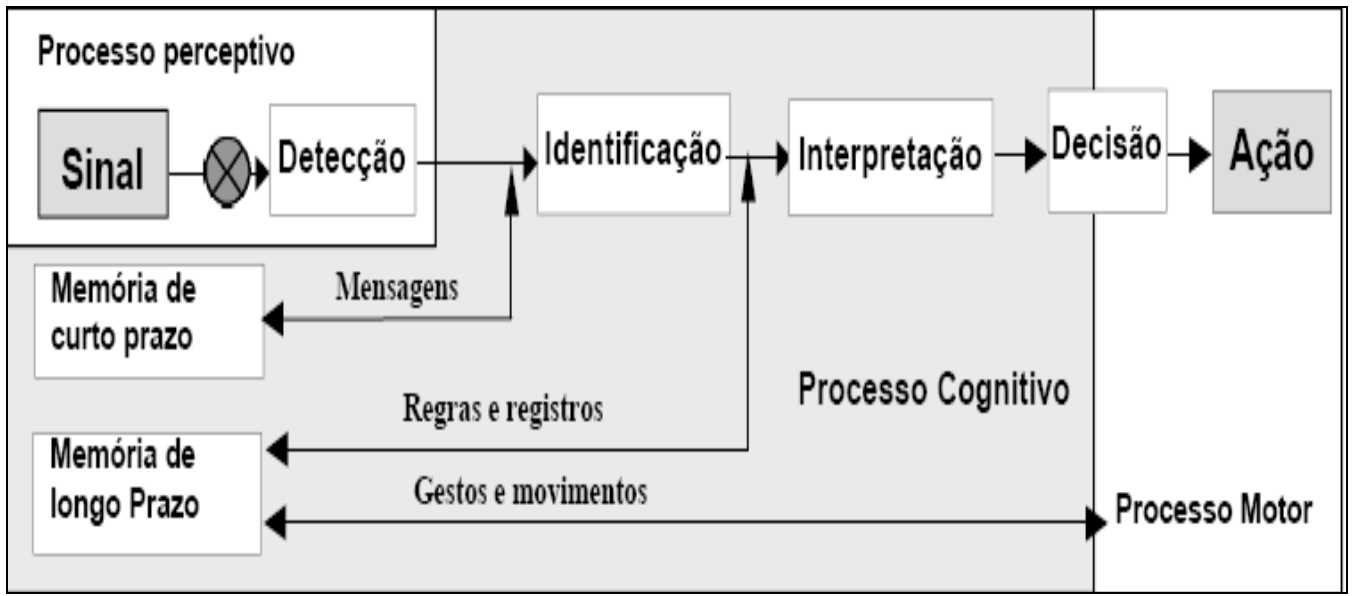

Dentro da complexidade e da inovação do tema de ergonomia cognitiva, este artigo aborda o principal aspecto observado nas empresas analisadas que foi a necessidade das empresas na redução de acidentes no trabalho por influência do trabalhador (fatores humanos) na realização de suas atividades tendo por base $o$ desenvolvimento $e$ participação em programa de treinamento a fim de contribuir na transformação do conhecimento em comportamento seguro. 
Treinamento é o processo educacional aplicado de maneira sistemática e organizado, através do qual, as pessoas apreendem conhecimentos, habilidades e atitudes em função de objetivos definidos. O desenvolvimento profissional é uma vertente mais abrangente que o treinamento que visa prover a educação como forma de desenvolver e aprimorar as pessoas em determinadas carreiras, organizações, ou para se tornarem mais eficientes e produtivas em seus cargos (Palmeira, 2004) apud (BORGHI, 2008). Hamblim (1974) define treinamento com uma seqüência de experiências e oportunidades desenhadas para modificar o comportamento ou qualquer atividade que tem como objetivo incrementar habilidades pessoais para o desempenho de uma tarefa apud (BORGHI, 2008).

Segundo Kirkpatrick (2010), esse é o mais elementar dos dês requisitos. Se o programa não suprir as necessidades dos participantes, os resultados da avaliação poderão ser desastrosos. A pesquisa foi realizada em três empresas dos segmentos de torrefação e moagem de café (empresa $A$ ), indústria e Comércio de Plástico (empresa $B$ ) e içamento e movimentação horizontal e vertical de cargas (empresa $\mathrm{C}$ ), localizadas no Estado de Pernambuco.

Este artigo apresenta os resultados das análises realizadas referente à realização de treinamentos após acidentes e a redução dos mesmos, contribuindo na transformação do comportamento dos trabalhadores nas três empresas de segmentos distintos conforme citado anteriormente. A escolha deve-se ao fato das empresas apresentadas possuírem setores de segurança de trabalho estruturados com funções claramente definidas.

\section{MÉTODO}

A pesquisa foi desenvolvida como estudo de caso (multi-caso) em 03 empresas envolvendo segmento industrial e de serviços. A pesquisa foi do tipo exploratória para observar resultados de desempenho na segurança do trabalho após a aplicação de treinamentos. $A$ pesquisa foi realizada em duas fases: a primeira referente à pesquisa bibliográfica no que diz respeito ao embasamento teórico sobre o tema para desenvolvimento da pesquisa prática. A segunda fase referente à pesquisa de campo com análise de relatórios de ocorrência de acidentes e treinamentos realizados com foco em segurança no trabalho.

Como instrumentos de coleta de dados na pesquisa documental foram considerados fontes primárias, tais como, documentos, relatórios da empresa objeto deste estudo e fontes secundárias como, por exemplo, registros dos acidentes no Ministério do Trabalho, informações disponíveis na internet, livros, artigos e jornais. Para a análise e interpretação de dados foram estudadas e desenvolvidas etapas de coleta sobre as ocorrências dos acidentes no trabalho nos anos de 2011 e 2012, análise das informações consolidadas por empresa, elaboração de ilustração gráfica para melhor entendimento. Foram também coletados dados realizada interpretação dos dados com o objetivo de se ter informações consolidadas e comparativas acerca do problema para o qual se busca obter resposta.

A partir dos relatórios fornecidos pelas empresas foi realizadas avaliação da relação entre os treinamentos realizados nos aspectos de segurança do trabalho e os acidentes do trabalho ocorridos posteriormente à aplicação dos treinamentos para demonstração do resultado alcançado na eficácia dos treinamentos.

Os acidentes de trabalho analisados serão classificados por típicos e de trajeto. E as causas identificadas nas análises desses acidentes serão estratificadas em fatores humanos e condições de trabalho.

\section{CONCLUSÃO}

Nas 3 empresas objeto de estudo desse artigo houve redução na ocorrência de acidentes típicos, ocorridos no local de trabalho, em relação ao período subsequente a realização dos treinamentos dos trabalhadores envolvidos com os acidentes conforme representado no gráfico1. 
Gráfico 1 - Ocorrência de acidentes típicos nas empresas estudadas

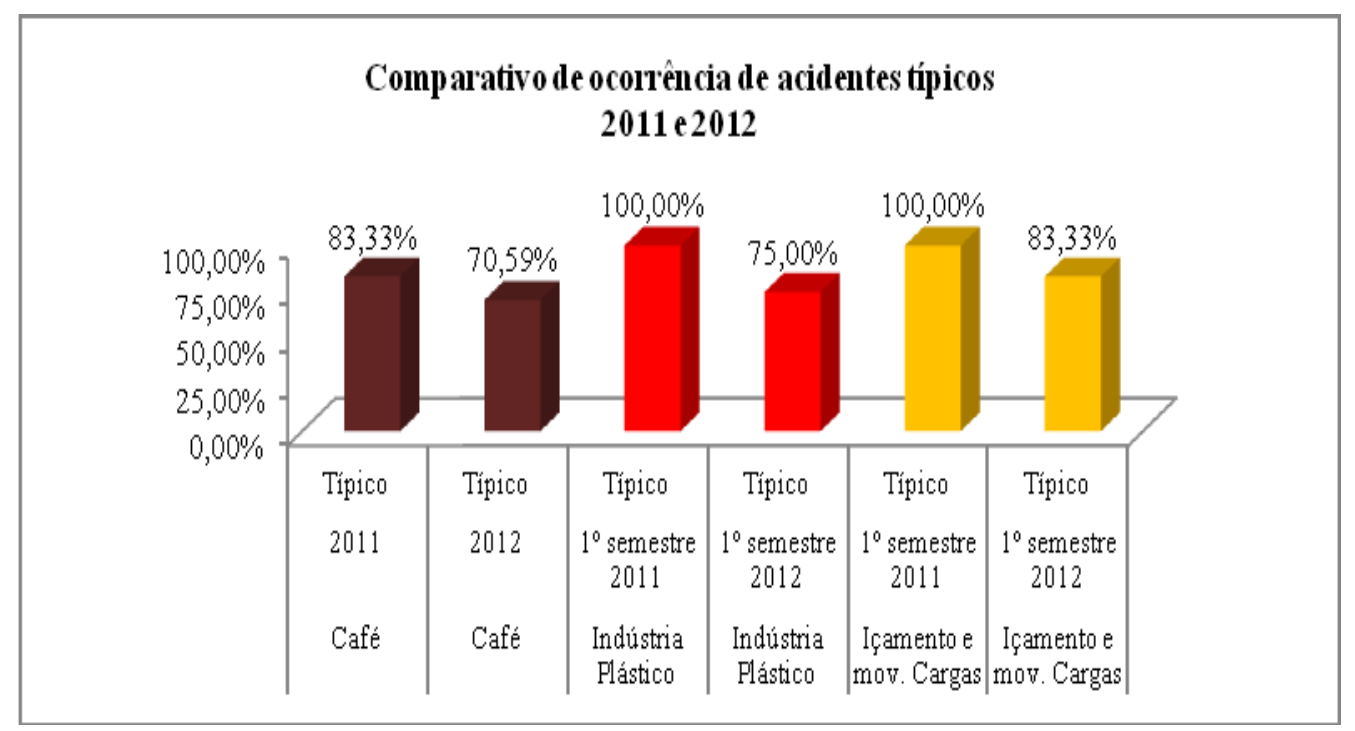

Fonte: produção do próprio autor

As 3 empresas estudadas tiveram redução de causas de acidentes por fatores humanos nos períodos posteriores à realização dos treinamentos abordando comportamento dos trabalhadores conforme gráfico 2 .

\section{Gráfico 2 - Causas identificadas dos acidentes típicos nas empresas estudadas}

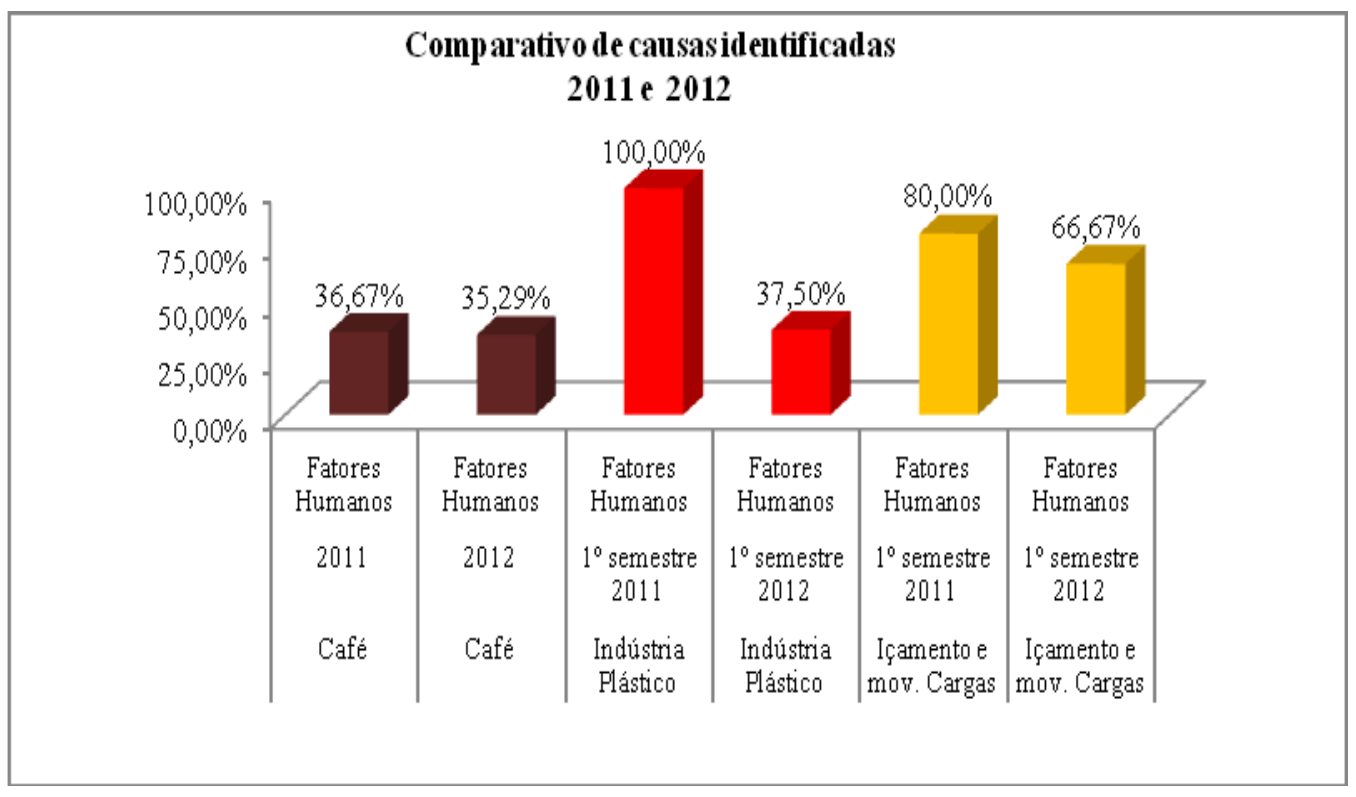

Fonte: produção do próprio autor 
As ações realizadas, após as ocorrências de acidentes típicos com causas identificadas associadas a fatores humanos, foram referentes à realização de treinamentos e reuniões abordando os fatores humanos. Entre as 3 empresas analisadas, 2 apresentaram redução de causas de fatores humanos envolvendo os acidentes de trabalho e em uma das empresas não houve aumento de número de acidentes típicos por fatores humanos entre 2012 e 2011. A empresa A obteve redução de $45,45 \%$ de causas de fatores humanos, a empresa B teve redução de $40,00 \%$ e na empresa C não houve aumento de causas devido a fatores humanos conforme gráfico 3 .

\section{Gráfico 3 - Causas identificadas dos acidentes típicos nas empresas estudadas}

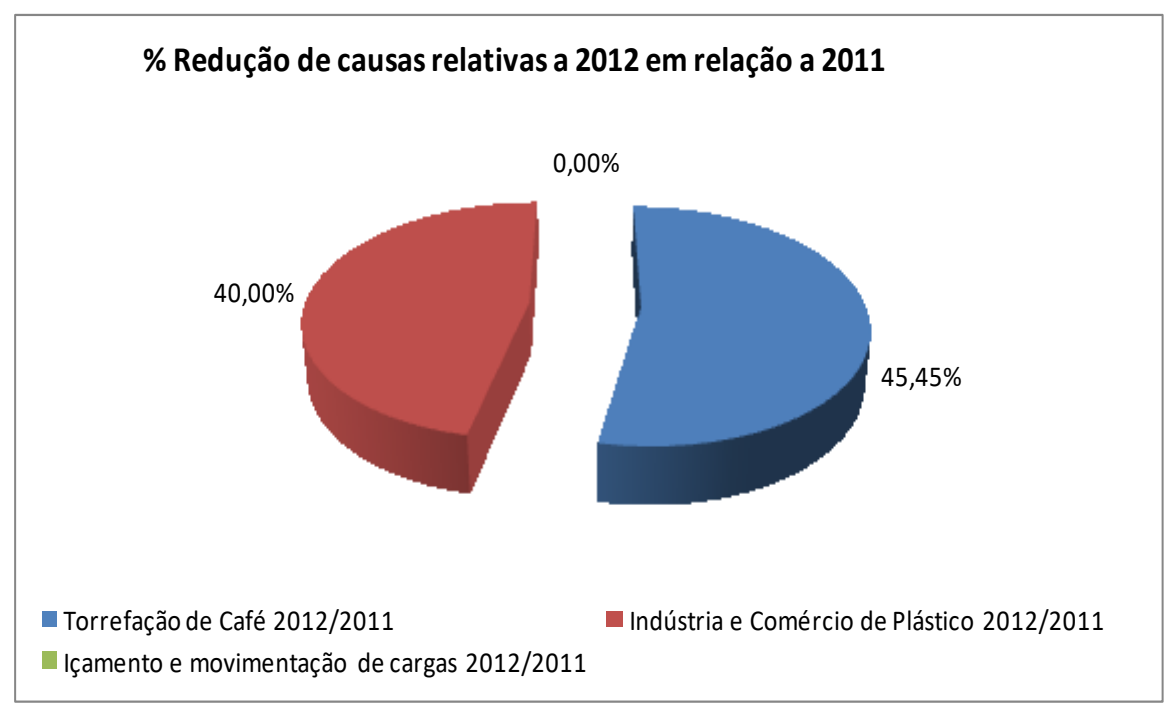

Fonte: produção do próprio autor

A redução dos fatores humanos apresenta-se como consequência da atenção dos trabalhadores a partir dos treinamentos realizados, tendo os funcionários melhorado o seu desempenho quanto à segurança no trabalho utilizando práticas mais seguras demonstrando que conseguiram transformar o conhecimento adquirido em comportamento. A importância dos treinamentos ficou evidente na transformação do conhecimento adquirido em comportamento dos trabalhadores em relação à segurança no trabalho.

Com a minha experiência observei que este estudo é relativamente novo no Brasil havendo bastante oportunidade de desenvolvimento tanto de pesquisa quanto de ferramentas que auxiliem os profissionais atuantes na segurança do trabalho quanto aos elementos cognitivos, capacitação e comportamento segurança dos trabalhadores que justificam investigações mais profundas sobre o tema.

Como sugestão para pesquisas futuras tem-se:

- A expansão do universo de aplicação deste estudo, uma vez que este estudo só permite conclusões sobre as empresas observadas, e não sobre o universo das empresas brasileiras.

- O desenvolvimento de questionário para identificação de fatores que mais influenciam no comportamento do trabalhador quanto aos aspectos de segurança no trabalho, bem como a aplicação do mesmo. 
- A identificação de fatores cognitivos que facilitem a transformação de conhecimento em comportamento seguro no que se refere à segurança no trabalho.

\section{REFERÊNCIAS BIBLIOGRÁFICAS}

ABRAHÃO, Júlia. Introdução à Ergonomia - da Prática à Teoria. São Paulo: Blucher, 2009. BORGHI, Layla D'lla KássiAa. Avaliação de resultados do Treinamento: Uma análise das Metodologias disponíveis e sua aplicação em empresas brasileiras. Dissertação (Mestrado profissionalizante em administração) - Faculdade de Economia e Finança/IBMEC, Rio de Janeiro, 2008.

KIRKPATRICK, Donald L. ; KIRKPATRICK, James.D. Como implementar os quatro níveis de avaliação de treinamento de equipes: um guia prático.Tradução de Alessandra Mussi. Rio de Janeiro: Senac Rio, 2010.Tradução de: Implementing the four levels: a practical guide for effective evaluation of training programs.

VIDAL, Mario Cesar. A certificação do ergonomista brasileiro, Editorial do Boletim 1/2000, Rio de Janeiro. 